\title{
Principales prácticas restrictivas a la libre competencia ejecutadas por los oferentes en el marco de procesos de selección de contratistas del Estado*
}

\author{
Main restrictive practices to free competition executed by the bidders in the \\ framework of selection processes of State contractors
}

Iván Humberto Galvis Macias**

Fecha de recepción: 10 de febrero de 2018

Fecha de aprobación: 10 de abril de 2018

\section{RESUMEN}

El derecho a la libre competencia económica, garantizado en el ordenamiento jurídico colombiano a partir de la prescripción contenida en el artículo 333 de la Constitución de 1991, encuentra su más legítima representación en el ámbito de la contratación estatal en el principio de libre concurrencia de oferentes, el cual resulta vulnerado a través de prácticas ejecutadas entre oferentes, e incluso entre estos y entidades estatales, con el ánimo de buscar beneficios en la selección de contratistas del Estado. Desde esta perspectiva, se hace necesario determinar cuáles son las principales prácticas ejecutadas por los oferentes en los procesos de selección de contratistas, que vulneran el derecho constitucional a la libre competencia y que han sido investigadas por la Superintendencia de Industria y Comercio (SIC), para lo cual se determinará

* El presente manuscrito es producto del proyecto de investigación: "Principales prácticas restrictivas a la libre competencia ejecutadas por los oferentes en el marco de procesos de selección de contratistas del Estado”, en el marco del programa de la Especialización en Contratación Estatal de la Universidad Santo Tomás, Seccional Tunja, Colombia. DOI: http://dx.doi.org/10.15332/s1909-0528.2018.0002.01

** Abogado egresado de la Universidad Santo Tomás, Seccional Tunja, Colombia, especialista en Derecho Constitucional de la Universidad Nacional de Colombia, magíster en Derecho con énfasis en Derecho Económico de la Universidad Externado de Colombia, docente universitario en programas de pregrado y posgrado en la Universidad Santo Tomás, Seccional Tunja, Colombia. Correo electrónico: ivan.galvis@usantoto.edu.co 
la naturaleza jurídica del derecho constitucional a la libre competencia en el marco de procesos de contratación estatal, se auscultará el papel de la Superintendencia de Industria y Comercio colombiana frente a la garantía de este derecho en procesos de contratación estatal, se determinará la posible aplicación de las prácticas restrictivas de la competencia tipificadas en el ordenamiento jurídico colombiano en procesos de selección de contratistas del Estado, y se analizarán algunos breves casos en los que la SIC aplicó medidas jurídicas en presuntos casos de prácticas colusorias, para de esta manera comprender la forma como tales prácticas se consolidan en los procesos de selección de contratistas adelantados por entidades estatales.

Palabras clave: libre competencia, libre concurrencia, prácticas restrictivas de la competencia, colusión, contratación estatal.

\section{Abstract}

The right to the free economic competition, guaranteed in the Colombian juridical arranging from the prescription contained in the article 333 of the Constitution of 1991, finds its most legitimate representation in the ambience of the state hiring in the beginning of offerors' free concourse, which turns out to be damaged across practices executed between offerors, and even between these and state entities, with the intention of looking for benefits in the selection of the State contractors. From this perspective it becomes necessary to determine what are the main practices executed by the offerors in the processes of contractors' selection that damage the constitutional law to the free competition and that have been investigated by the Supervision of Industry and Commerce, for which the juridical nature of the constitutional law will determine to the free competition in the frame processes of state hiring, there will be auscultated the role of the Colombian Supervision of Industry and Commerce opposite to the guarantee of this right in processes of state hiring, there will decide the possible application of the restrictive practices of the competition typified in the Colombian juridical arranging in processes of contractors' selection of the State, and there will be analyzed some brief cases in which the SIC applied juridical measurements in supposed cases of collusive practices, this way to understand the form as such practices are consolidated in the processes of selection of contractors moved forward by state entities.

Keywords: free competition, free concurrency, restrictive of competition, collusion, state contracts. 


\section{INTRODUCCIÓN}

La libre competencia económica ha sido reconocida en el ordenamiento jurídico colombiano como un derecho de carácter económico y a la vez colectivo, que además de tal significación, comporta una vital relevancia para el desarrollo de las relaciones económicas y, con ello, para la efectiva garantía del modelo económico constituido a partir de la vigencia de la Constitución de 1991.

$\mathrm{Al}$ ser entonces la libre competencia económica un principio medular en la implementación del modelo de economía social de mercado que debe desarrollarse en nuestro Estado social de derecho ${ }^{1}$, resulta fundamental la realización de un análisis de aplicación de este derecho en las relaciones económicas (mercados) que surgen de los procesos de adquisición de bienes y servicios desarrollados por las entidades estatales, y de esta manera determinar qué prácticas ejecutadas por los oferentes en tales procesos, resultan atentatorias de la garantía efectiva de la libre competencia.

Tal propósito encuentra su fundamento en la evidente necesidad de esclarecer las razones por las cuales el máximo órgano estatal encargado de la garantía de la libre competencia económica en Colombia, investiga y sanciona agentes económicos, derivados de las conductas por ellos cometidas en el desarrollo de procesos de selección de contratistas del Estado, sin perjuicio de las investigaciones y sanciones que resulten de la declaratoria de responsabilidad penal o disciplinaria que aquellas conductas comporten.

En tal sentido, el esclarecimiento pretendido se dirigirá a determinar - como ya se ha anotado-, que la libre competencia económica no es un derecho cuya aplicación se limite únicamente al desarrollo de relaciones económicas celebradas entre particulares, sino que aquel también se extiende a los mercados que genera cada uno de los procesos de contratación convocados por el Estado, que al constituirse como "mercados específicos", deben caracterizarse por la libre concurrencia de agentes que compitan por suministrar los bienes y servicios requeridos.

1 Es importante resaltar que: "La Constitución Política declara que Colombia es un Estado social y democrático de derecho con lo que impone una caracterización precisa que permite distinguirlo de otros modelos superados o por lo menos de los que ha evolucionado" (Arias, 2017, p. 64). 
De esta manera, la finalidad aquí propuesta se abordará a través de un breve análisis de la aplicación y naturaleza jurídica que ostenta el derecho a la libre competencia económica en el ámbito de los procesos de selección de contratistas desarrollados por las distintas entidades del Estado colombiano, para de esta forma, ahondar en la importancia que asume el papel de la Superintendencia de Industria y Comercio colombiana - como máximo órgano instituido para la garantía efectiva de este derecho-, en el reconocimiento y garantía de este principio en el ámbito de la contratación estatal.

Seguido a ello, se procederá a determinar la posible aplicación de las prácticas restrictivas de la competencia tipificadas en el ordenamiento jurídico colombiano al ámbito de los mercados específicos creados en los procesos de contratación del Estado, para de esta forma concluir, a partir de la breve narración de algunos casos desarrollados por la Superintendencia de Industria y Comercio, cómo las prácticas colusorias se concretan en la conducta de los oferentes que participan en estos procesos.

Tal pretensión se realizará a través de una metodología cualitativa, en la que se describirán las principales características y elementos que permitan definir el derecho a la libre competencia en el marco de procesos de selección de contratistas del Estado, y de esta manera, determinar la aplicabilidad de las prácticas que restringen la competencia económica, tipificadas en la legislación colombiana a los procesos de contratación estatal. En este orden de ideas, la investigación se enmarca dentro de la perspectiva teórica de diversos autores (Puentes, 2017) y sus respectivos enfoques y por los marcos normativo y jurisprudencial respecto de la temática en análisis.

El presente estudio se consolida entonces, para aportar un nuevo eje de reflexión en torno a la conjugación de dos ramas del derecho sustancialmente distintas (derecho de la competencia y derecho de la contratación estatal), que desde la clásica división de la ciencia jurídica en derecho público y privado, han conocido pocos puntos de convergencia y que ahora se integran con el fin de alcanzar propósitos de superior relevancia constitucional, como lo son la garantía de derechos constitucionales económicos y la consolidación efectiva del modelo económico asumido por la Constitución Política de 1991. 


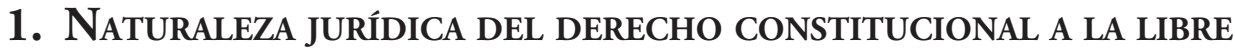 COMPETENCIA EN EL MARCO DE LA CONTRATACIÓN ESTATAL}

El ordenamiento jurídico colombiano ha asumido un modelo económico específico a partir de la vigencia de la Constitución Política de 1991, que se fundamenta en el reconocimiento y garantía de la libertad económica como género de derechos cuya importancia ostenta evidente claridad.

El reconocimiento de la libertad económica en el marco del modelo de economía social de mercado supone la garantía efectiva de los derechos de naturaleza económica reconocidos en el artículo 333 constitucional, que por su parte corresponden a la libertad de empresa y la libre competencia ${ }^{2}$, entendido el primero como:

[...] aquella libertad que se reconoce a los ciudadanos para afectar o destinar bienes de cualquier tipo (principalmente de capital) para la realización de actividades económicas para la producción e intercambio de bienes y servicios conforme a las pautas o modelos de organización típicas del mundo económico contemporáneo con vistas a la obtención de un beneficio o ganancia (Corte Constitucional, noviembre 16 de 1995).

La libre competencia económica, por su parte,

[...] acontece cuando un conjunto de empresarios o de sujetos económicos, bien se trate de personas naturales o jurídicas, dentro de un marco normativo y de igualdad de condiciones, ponen sus esfuerzos o recursos a la conquista de un mercado de bienes y servicios en el que operan otros sujetos con intereses similares. Se trata propiamente de la libertad de concurrir al mercado ofreciendo determinados bienes y servicios, en el marco de la regulación y en la ausencia de barreras u obstáculos que impidan el despliegue de la actividad económica lícita que ha sido escogida por el participante ${ }^{3}$ (Corte Constitucional, enero 25 de 2017).

2 Lo dispuesto debe entenderse en correspondencia con lo establecido por Trujillo (2018), y que resulta de importancia para articular la libertad de empresa con la contratación estatal, en este sentido, para el citado autor, "El estudio de las instituciones es uno de los enfoques que ofrece la ciencia política que se emplea para el análisis de la administración pública. Se concentra en el estudio de las incitaciones formales y no formales que orientan la acción colectiva" (p. 148).

3 Lo dispuesto no implica no olvidar la importancia de las tecnologías de la información y las comunicaciones (TIC), las cuales son unas de las principales características de la actual sociedad del conocimiento (Gómez, 2017). 
En tal sentido, según lo ha reconocido la misma Corte Constitucional colombiana, el derecho a la libre competencia comprende la posibilidad de que el empresario o sujeto económico: i) concurra de manera libre al mercado, ii) ofrezca las condiciones y ventajas que considere al consumidor de sus productos o servicios y, iii) contrate con cualquier consumidor o usuario el suministro o prestación de los mismos, lo que por su parte implica entender a la libre competencia como sinónimo de libertad de concurrencia al mercado.

Con fundamento en lo anterior, se entiende que la libre competencia es un derecho de naturaleza económica, cuyo núcleo esencial "[...] consiste en la posibilidad de acceso al mercado por parte de los oferentes sin barreras injustificadas [...]" (Corte Constitucional, marzo 24 de 2010) $)^{4}$.

La libre competencia no resulta ser un derecho de menor importancia en el ordenamiento jurídico colombiano, sino que por el contrario constituye el escenario básico para el reconocimiento y garantía de los derechos económicos de los ciudadanos, a tal punto que se la ha reconocido con una doble naturaleza: por un lado, se le concibe como un derecho de carácter individual frente al cual cada individuo que, en el ejercicio de su libertad económica, vea cercenada su posibilidad de concurrir al mercado, puede reivindicarlo a través de los mecanismos procesales dispuestos para tal fin en el ordenamiento, y por el otro, como un derecho de la colectividad frente al cual, cualquier ciudadano puede requerir del Estado su protección por vía jurisdiccional, pues los principales sujetos que se benefician de su garantía son los consumidores (Tirole, 2017, p. 381) .

4 Estos derechos de naturaleza económica deben ser garantizados a todos los asociados al Estado colombiano en virtud de la disposición contenida en el artículo 333 superior, que por su parte reconoce a la libertad de empresa como motor del desarrollo económico, y estatuye la libre competencia como una condición necesaria para la efectiva garantía de la libertad económica, que por su parte ha de ser reconocida a estos asociados no solo en el ámbito de las relaciones económicas celebradas entre particulares, sino que también se extiende — como a continuación se señalará- a las dinámicas de producción y prestación de bienes y servicios a las entidades del Estado, bajo el marco conceptual de la contratación estatal.

5 Así lo explica Magdalena Correa (2009), al expresar que: “[...] se concibe la libre competencia económica como un derecho individual y, a la vez, colectivo (art. 88 de la Constitución), en tanto derecho cuya finalidad no es otra que 'alcanzar un estado de competencia real, libre y no falseada, que permita la obtención de lucro individual para el empresario' y por el cual se generan 'beneficios para el consumidor con bienes y servicios de mejor calidad, con mayores garantías y a un precio real y justo"” (p. 574). 
Al concebir entonces el derecho a la libre competencia como un derecho de carácter individual, resulta de vital importancia analizar su aplicación y alcance en el ámbito de la contratación estatal, pues — como se ha señalado hasta el momento- este corresponde a un derecho que no debe ser reconocido y garantizado de manera limitada al desarrollo de las relaciones económicas que celebran los particulares, sino que el mismo también se extiende a aquellas dinámicas de provisión de bienes y servicios a las entidades estatales en el marco de la normatividad vigente que regula los procesos de selección de contratistas del Estado.

La importancia de este derecho en el ámbito de la contratación estatal es evidente, pues, como lo reconoce Tirole (2017) al establecer las seis maneras con las cuales el Estado se inserta en el núcleo de las relaciones económicas en una economía de mercado,
[a] través de los mercados públicos, el Estado es el comprador y, por tanto, organiza la competencia entre proveedores: construcción de edificios públicos, concesiones de transportes (autopistas, transporte ferroviario, urbano), equipamientos para hospitales y otras colectividades, etcétera (p. 379).

Pero al mismo tiempo, este también actúa "[...] como árbitro de los mercados, vela por la competencia, es garante de la innovación y de que los productos sean accesibles al consumidor" (p. 379).

De esta manera, ha de entenderse que el Estado actúa con una doble intención frente al reconocimiento y garantía del derecho a la libre competencia ${ }^{6}$ : la primera, garantizando que los oferentes en el mercado ejecuten su actividad sin ningún tipo de restricción injustificada, caso en el cual actuará como árbitro de los mercados regulando los escenarios en los que estos presenten fallas y sancionando a quien incurra en prácticas que restrinjan el libre acceso a los mercados; y la segunda, frente a la cual este actúa como comprador, y por lo mismo organiza la libre concurrencia de

6 Es preciso aclarar que: "El deber de mitigar los dańos es, en principio, ajeno al sistema de derecho europeo continental. A manera de ejemplo, en Colombia solo está consagrado de forma expresa y especial para el contrato de seguros, en el artículo 1074 del Código de Comercio. Adicionalmente, se contempla en el artículo 77 de la Convención de Naciones Unidas sobre los Contratos de Compraventa Internacional de Mercaderías de 1980, adoptada en Colombia mediante la Ley 518 de 1999 y en vigor desde el 1 de agosto de 2002" (Barone, 2018). 
proveedores, para que presten sus servicios o suministren sus bienes a las entidades estatales en igualdad de condiciones.

Será la segunda intención aquí referida la que determine la naturaleza jurídica de la libre competencia en el marco de la contratación estatal, pues es en esta en la que el Estado no actúa como ente regulador y garante de la libertad de concurrencia a los mercados privados, sino como consumidor de bienes y servicios, y como consecuencia de ello, garante de la libre competencia entre sus proveedores.

En tal sentido, la regulación jurídica de la contratación estatal en Colombia ha reconocido y aplicado un catálogo de principios orientadores que deben ser asumidos obligatoriamente por las entidades estatales en todos los procesos de selección de sus contratistas, entre los cuales se encuentra la libre competencia económica ${ }^{7}$.

Puede evidenciarse que el contenido de la libertad de concurrencia - como principio propio de la contratación estatal en Colombia_- presenta similitud de contenidos con la libre competencia económica, pues — como lo definió la Corte Constitucional colombiana-, el núcleo esencial de la segunda corresponde a la garantía del particular de acceder al mercado sin ningún tipo de restricción injustificada, en tanto que la libre concurrencia implica la prohibición de que la administración imponga condiciones restrictivas a la participación de los oferentes en los procesos de selección ${ }^{8}$.

7 Sin embargo, es preciso aclarar que la regulación de la contratación estatal no concibe el principio de libre competencia bajo esta denominación, sino que este se encuentra contenido en lo que la jurisprudencia — tanto constitucional como contencioso-administrativa - ha reconocido bajo la denominación del principio de libre concurrencia, aunque en la definición de uno u otro se utilicen de manera concomitante los términos 'competencia' y 'concurrencia' como sinónimos. Frente a esta particular denominación, el máximo tribunal de la jurisdicción contencioso-administrativa de Colombia, ha afirmado que: "La libre concurrencia, conlleva, entonces, a la no discriminación para el acceso en la participación dentro del proceso de selección, a la vez que posibilita la competencia y oposición entre los interesados en la contratación. Consecuencia de este principio es el deber de abstención para la administración de imponer condiciones restrictivas que impidan el acceso al procedimiento de selección, por lo que resulta inadmisible la inclusión en los pliegos de condiciones de cláusulas limitativas que no se encuentren autorizadas por la Constitución y la ley, puesto que ellas impiden la más amplia oportunidad de concurrencia y atentan contra los intereses económicos de la entidad contratante, en razón a que no permiten la consecución de las ventajas económicas que la libre competencia del mercado puede aparejar en la celebración del contrato" (Consejo de Estado, diciembre 3 de 2007).

8 Así también lo ha reconocido la Honorable Corte Constitucional al anunciar que: "La jurisprudencia constitucional ha reconocido que el derecho a la igualdad de oportunidades, aplicado a la contratación de la administración pública, se plasma en el derecho a la libre concurrencia u oposición, según el cual, se garantiza la 
De la misma manera, la libre competencia implica para el empresario la posibilidad de: i) ingresar de manera libre al mercado, ii) ofrecer las condiciones y ventajas que considere al consumidor de sus productos o servicios y, iii) contratar con el consumidor o usuario el suministro o prestación de los mismos; en tanto que la libre concurrencia supone la posibilidad de que el oferente: i) participe en los procesos de selección de contratistas del Estado, razón por la cual la entidad no puede imponer restricciones que impidan el acceso de los interesados a determinado proceso de selección, ii) ofrezca un catálogo de ventajas — dentro de los límites de sus posibilidades económicas y empresariales_ para que sea la entidad la que, a través de un proceso de selección objetiva, elija las que le resulten más favorables y, iii) contrate con la entidad a la cual libremente haya decidido presentar su oferta.

Frente a lo anterior, debe reconocerse que en el marco de la contratación estatal la libertad de concurrencia supone libertad en la participación de procesos de selección de contratistas del Estado sin la existencia de barreras de acceso injustificadas, lo que no significa que la misma conlleve la posibilidad de que el oferente favorecido con la adjudicación de un proceso de selección goce de la autonomía para decidir si contrata o no con la entidad luego de adjudicado el contrato, o lo que es lo mismo: si suscribe o no el contrato adjudicado, pues como se desprende de la regulación de la contratación estatal:

De la adjudicación nace la obligación y el derecho correlativo de las partes de suscribir el contrato dentro del término fijado en los pliegos de condiciones, esto es, que hace

facultad de participar en el trámite concursal a todos los posibles proponentes que tengan la real posibilidad de ofrecer lo que demanda la administración. La libre concurrencia, entraña, la no discriminación para el acceso en la participación dentro del proceso de selección, a la vez que posibilita la competencia y oposición entre los interesados en la contratación. Consecuencia de este principio es el deber de abstención para la administración de imponer condiciones restrictivas que impidan el acceso al procedimiento de selección, por lo que resulta inadmisible la inclusión en los pliegos de condiciones de cláusulas limitativas que no se encuentren autorizadas por la Constitución y la ley, puesto que ellas impiden la más amplia oportunidad de concurrencia y atentan contra los intereses económicos de la entidad contratante, en razón a que no permiten la consecución de las ventajas económicas que la libre competencia del mercado puede aparejar en la celebración del contrato. Sin embargo, la libertad de concurrencia, admite excepciones fijadas por el legislador, con sujeción a parámetros de razonabilidad y proporcionalidad, que pueden tener como fundamento la necesidad de asegurar la capacidad legal, la idoneidad moral o las calidades técnicas, profesionales, económicas y financieras del contratista, además de la posibilidad que tiene el Estado de establecer inhabilidades e incompatibilidades para asegurar la transparencia en el proceso de contratación estatal" (Corte Constitucional, octubre 7 de 2009). 
nacer una relación jurídica vinculante entre administración y oferente adjudicatario [...]. Los efectos por la no suscripción del contrato por causas imputables al adjudicatario varían según exista de por medio justa causa o no (Dávila, 2016, p. 446).

En este orden de ideas, la libertad de concurrencia resulta ser el principio propio de la contratación estatal en el que se reconoce y garantiza la libre competencia económica en los procesos de selección de contratistas del Estado, pues el contenido y alcance de las dos figuras resultan ser estrictamente similares, razón por la cual, con frecuencia, se alude a cada una de ellas con la denominación de la otra; el único aspecto que las diferencia se concreta en que en la libre competencia económica el empresario cuenta con la autonomía de decidir si contrata o no con un consumidor determinado, garantizando por supuesto todos los derechos y garantías que se desprenden de su condición, en tanto que en la contratación estatal el principio de libre concurrencia se limita a garantizar la participación de los oferentes en los procesos de selección en igualdad de oportunidades y sin barreras o restricciones de acceso injustificadas, más no a la libertad de suscribir el correspondiente contrato, pues como se anotó, del acto de adjudicación del contrato surge la obligación mutua de las partes de suscribir el respectivo contrato estatal?.

En consecuencia, la naturaleza jurídica del derecho a la libre competencia en el marco de la contratación estatal en Colombia ha de entenderse como un principio orientador al que deben sujetarse todas las entidades estatales y conforme al cual estas deben garantizar la libre concurrencia de oferentes a los distintos procesos de selección, sin la imposición de barreras de acceso injustificadas que eliminen las ventajas económicas de la libertad competitiva.

9 Desde esta perspectiva, como lo afirma el Consejo de Estado colombiano: "[...] se concluye que de acuerdo con la jurisprudencia y la doctrina el principio de libre concurrencia consiste en la igualdad de oportunidades de acceso a la participación en un proceso de selección contractual (art. 13. C. P.), y a la oposición y competencia en el mismo, de quienes tengan la real posibilidad de ofrecer lo que demanda la administración, en el marco de las prerrogativas de la libertad de empresa regulada en la Constitución Política, destinada a promover y estimular el mercado competitivo (arts. 333 y 334 C. P.)” (Consejo de Estado, diciembre 3 de 2007). 


\section{El papel de la Superintendencia de Industria y Comercio EN LA PROTECCIÓN DEL DERECHO CONSTITUCIONAL A LA LIBRE COMPETENCIA EN EL MARCO DE LA CONTRATACIÓN ESTATAL}

Habiéndose realizado un análisis en torno al alcance jurídico que ostenta la libre competencia en el desarrollo de los procesos de selección de contratistas del Estado, se hace necesario ahora efectuar una breve descripción del fundamento y competencia que la legislación colombiana le atribuye a la Superintendencia de Industria y Comercio como garante de la libre competencia en el mercado en nuestro aparato institucional, y de manera específica, de la importancia que su función ostenta en la protección de la libre concurrencia en los procesos de selección de contratistas del Estado $^{10}$.

Las superintendencias se constituyen en organismos institucionales que integran la administración nacional en los sectores central y descentralizado, cuyas funciones y facultades han de estar determinadas por lo que para tal efecto disponga el legislador.

Con todo lo anterior, el legislador colombiano determinó la creación de estos organismos en los preceptos contenidos en los artículos 66 y 82 de la Ley 489 de 1998, para el cumplimiento de las funciones dispuestas en los numerales 21,22 y 24 del artículo 189 y en el artículo 211 de la Constitución de 1991.

A la Superintendencia de Industria y Comercio se le constituyó como entidad encargada de velar por la protección de la libre competencia económica y de aplicar las sanciones dispuestas en el ordenamiento jurídico a los agentes que las infrinjan, pues, como se desprende de las funciones dispuestas en el numeral primero del artículo 2 del Decreto 2153 de 1992, modificado por el artículo 3 de la Ley 1340 de 2009, y

10 En este orden de ideas, ha de reconocerse que la misma Constitución Política de 1991 determinó la incorporación de las superintendencias en la estructura orgánica del nivel central y descentralizado del aparato estatal, al disponer en el numeral séptimo del artículo 150 superior, que es función del Congreso de la República: "Determinar la estructura de la administración nacional y crear, suprimir o fusionar ministerios, departamentos administrativos, superintendencias, establecimientos públicos y otras entidades del orden nacional, señalando sus objetivos y estructura orgánica; reglamentar la creación y funcionamiento de las Corporaciones Autónomas Regionales dentro de un régimen de autonomía; así mismo, crear o autorizar la constitución de empresas industriales y comerciales del Estado y sociedades de economía mixta”. 
por el numeral segundo del artículo 2 del Decreto 2153 de 1992, le corresponde a esta entidad:

1. Velar por la observancia de las disposiciones sobre protección de la competencia; atender las reclamaciones o quejas por hechos que pudieren implicar su contravención y dar trámite a aquellas que sean significativas para alcanzar en particular los siguientes propósitos: la libre participación de las empresas en el mercado, el bienestar de los consumidores y la eficiencia económica. [Y]

2. Imponer las sanciones pertinentes por violación de las normas sobre prácticas comerciales restrictivas y promoción de la competencia, así como por la inobservancia de las instrucciones que, en desarrollo de sus funciones imparta la Superintendencia.

Desde esta perspectiva, se debe considerar que, conforme a las disposiciones normativas previamente analizadas y a las demás funciones dispuestas en el artículo 1 del Decreto 4886 de 2011 y en la Ley 1340 de 2009, la Superintendencia de Industria y Comercio ejerce las funciones de inspección, vigilancia y control en relación con el aseguramiento y garantía del derecho constitucional a la libre competencia en sus núcleos esenciales de libre acceso al mercado o libre concurrencia a los procesos de contratación estatal, ofrecimiento de condiciones y ventajas más favorables al consumidor o a la respectiva entidad, y libertad de contratación con el consumidor y bajo las restricciones analizadas en el acápite anterior en relación con el acto de adjudicación de los contratos estatales ${ }^{11}$.

11 Tal afirmación se soporta en el alcance dado por la Corte Constitucional colombiana a las funciones de inspección, vigilancia y control, quien en su jurisprudencia ha reconocido que: "Las funciones de inspección, vigilancia y control se caracterizan por lo siguiente: (i) la función de inspección se relaciona con la posibilidad de solicitar y/o verificar información o documentos en poder de las entidades sujetas a control, (ii) la vigilancia alude al seguimiento y evaluación de las actividades de la autoridad vigilada y, (iii) el control en estricto sentido se refiere a la posibilidad del ente que ejerce la función de ordenar correctivos, que pueden llevar hasta la revocatoria de la decisión del controlado y la imposición de sanciones. Como se puede apreciar, la inspección y la vigilancia podrían clasificarse como mecanismos leves o intermedios de control, cuya finalidad es detectar irregularidades en la prestación de un servicio, mientras el control conlleva el poder de adoptar correctivos, es decir, de incidir directamente en las decisiones del ente sujeto a control" (Corte Constitucional, julio 18 de 2012). 
Las funciones de inspección y vigilancia para el aseguramiento del derecho constitucional a la libre competencia ejercidas por la Superintendencia de Industria y Comercio, se concretan en la facultad prevista en el numeral primero del artículo 2 del Decreto 2153 de 1992, modificado por el artículo 3 de la Ley 1340 de 2009, conforme a la cual esta puede solicitar y verificar información dentro de los trámites que desarrolle con fundamento en las reclamaciones o quejas que se le interpongan por hechos que contravengan las disposiciones sobre protección de la libre competencia, así como realizar el seguimiento y evaluación de las actuaciones de las empresas o agentes económicos que las incumplan.

De otro lado, la función de control atribuida a la SIC se verifica en la disposición contenida en el numeral segundo del artículo 2 del Decreto 2153 de 1992, conforme a la cual esta puede imponer sanciones por el incumplimiento de las normas existentes en el ordenamiento jurídico sobre protección de la libre competencia, así como por el incumplimiento de las órdenes emitidas por la SIC en el desarrollo de los trámites que esta adelante.

Con todo lo anterior, el papel de la Superintendencia de Industria y Comercio frente a la protección del derecho constitucional a la libre competencia, tanto en las relaciones económicas privadas, como en la garantía del principio de libre concurrencia en los procesos de selección de contratistas del Estado, ostenta una evidente relevancia, pues como se ha anotado hasta aquí, es a esta institución a la que el ordenamiento jurídico colombiano le otorgó las facultades de investigar, tomar medidas jurídicas y sancionar a los agentes que, con sus conductas, violen las preceptivas jurídicas de protección a la libre competencia, preceptivas que, como se analizará en el acápite subsiguiente, no solo involucran conductas en las que se vean inmersos agentes exclusivamente privados, sino que también atañen a conductas que se ejecutan en el marco de procesos de selección de contratistas del Estado, en los que actúan agentes económicos privados y entidades de derecho público.

Desde esta perspectiva, al reconocerse la trascendental importancia que ostenta el principio de la libre concurrencia — previamente analizado en el presente trabajoen el marco de procesos de selección de contratistas del Estado, también resulta evidente la importante función que desarrolla la Superintendencia de Industria y Comercio en su papel institucional de garante del principio de la libre competencia 
en las relaciones económicas privadas y en aquellas que se derivan de los procesos de contratación estatal ${ }^{12}$.

Al ser la Superintendencia de Industria y Comercio la institución que debe garantizar la libre competencia en los mercados colombianos — como ya se anotó al describir sus atribuciones funcionales-, y al reconocer que los procesos de contratación pública aportan un amplio margen de crecimiento a la economía colombiana, por lo que deben ser protegidos de prácticas que restrinjan la libre concurrencia de oferentes, no cabe duda que esta entidad asume un papel sumamente importante en el reconocimiento y garantía de este derecho constitucional en el ámbito de la contratación estatal.

Esta proposición se encuentra soportada no solamente en los argumentos previamente expuestos y en el reconocimiento que la misma SIC presenta sobre la aplicación de sus funciones en los procesos de selección de contratistas del Estado, sino además, en las recomendaciones formuladas al Estado colombiano por la Organización para la Cooperación y el Desarrollo Económicos en informe del Secretariado sobre el marco jurídico y las prácticas de contratación pública de Colombia, en donde la organización internacional, refiriéndose a la práctica de conductas anticompetitivas en el marco de procesos de contratación estatal, dispuso que "[...] es esencial que los países aprueben leyes para abordar estos tipos de actividades y que establezcan

12 Tal afirmación encuentra su fundamento en el reconocimiento que la misma Superintendencia asume, frente al derecho a la libre competencia en el marco de procesos de contratación estatal, pues esta afirma que: "La colusión no es una conducta que afecta solamente a los demás oferentes que no participaron en un acuerdo colusorio, sino que consecuentemente tiene un impacto directo en el mercado al incrementar los precios de los bienes y servicios contratados, generando así desequilibrios en el gasto público. En efecto, los contratos estatales representan valiosas oportunidades de negocios para cualquier particular. Esta característica los hace nichos propicios para la colusión en virtud del tamaño de las contrataciones, los montos involucrados y la complejidad en la normatividad. Según estudios de la Organización para la Cooperación y el Desarrollo Económico (OCDE), las adquisiciones del sector público representan hasta el $15 \%$ del Producto Interno Bruto (PIB), lo que convierte a la contratación pública en un componente importante de la actividad económica de cualquier país, y hace a su vez urgente y necesario el diseño de políticas orientadas a la disminución y detección de la colusión en las licitaciones públicas" (Superintendencia de Industria y Comercio, s. f., p. 8). De la misma manera, la Superintendencia de Industria y Comercio ha reconocido la importancia de la libre competencia en procesos de contratación estatal, al afirmar que: "El régimen de libre competencia económica en el contexto de la contratación estatal tiene entre sus propósitos fundamentales el que todos los proponentes puedan acceder con igualdad de oportunidades a formular sus ofertas y, además, que de ese ejercicio de autonomía y de sana rivalidad se obtengan las mejores condiciones de contratación para el Estado" (Superintendencia de Industria y Comercio, abril 19 de 2017). 
autoridades de competencia con suficientes facultades y sanciones para disuadir estas acciones anticompetitivas" (OCDE, 2014, p. 11).

De esta forma, no resulta ser menor la responsabilidad atribuida legalmente a la Superintendencia de Industria y Comercio ${ }^{13}$, quien como garante del derecho constitucional a la libre competencia en el ordenamiento jurídico colombiano, debe propender por el reconocimiento y garantía de este derecho en todas las relaciones económicas que se celebren en el mercado colombiano, incluso aquellas que se derivan de los procesos de contratación de bienes y servicios para las entidades estatales, bajo el reconocimiento del principio de la libre concurrencia.

\section{Principales prácticas ejecutadas por los oferentes en PROCESOS DE CONTRATACIÓN ESTATAL, QUE VULNERAN EL DERECHO CONSTITUCIONAL A LA LIBRE COMPETENCIA}

Para hablar de prácticas restrictivas del derecho constitucional a la libre competencia, ejecutadas por oferentes en el marco de procesos de selección de contratistas del Estado, se hace necesario hacer referencia en primer término a lo que la doctrina jurídica ha entendido por "prácticas restrictivas de la competencia".

En tal sentido, resulta pertinente - como primera medida - hacer una breve mención de los principales preceptos normativos que establecen las denominadas prácticas restrictivas, para de esta forma continuar con una breve explicación acerca de los tipos de prácticas dispuestos en la normatividad vigente, y de esta manera ahondar en las prácticas que se enmarcan en el ámbito de la contratación estatal.

Es así como el artículo primero de la Ley 155 de 1959, modificado por el Decreto 3307 de 1963, dispuso de una cláusula general de protección al derecho a la libre competencia económica — también denominada prohibición general—, en la

$13 \mathrm{Al}$ respecto, "bajo el mandato constitucional consagrado en el artículo 90 de nuestra Carta Política, Colombia se ha constituido como un Estado garantista de los derechos de sus administrados en materia de responsabilidad, indicándose que el Estado es responsable de los dańos que ocasione a los particulares no solo por sus acciones sino también por sus omisiones" (Castro, 2018, p. 170). 
que proscribió la celebración de cualquier acuerdo o convenio que limitase la libre competencia o que estuviese dirigido a determinar los precios en el mercado, en los siguientes términos:

Quedan prohibidos los acuerdos o convenios que directa o indirectamente tengan por objeto limitar la producción, abastecimiento, distribución o consumo de materias primas, productos, mercancías o servicios nacionales o extranjeros, y en general, toda clase de prácticas, procedimientos o sistemas tendientes a limitar la libre competencia y a mantener o determinar precios inequitativos.

De esta prohibición general se infiere la estructuración de lo que pudiera entenderse como un primer tipo de prácticas restrictivas referidas a la celebración de acuerdos que restringen la libre competencia de los agentes económicos en los mercados, que en la actualidad están asociadas a prácticas de cartelización.

Sin embargo, no ha sido la Ley 159 de 1959 la única norma jurídica que ha dispuesto la totalidad de los tipos de prácticas comerciales restrictivas, también ha hecho lo propio el artículo 46 del Decreto 2153 de 1992 y las adiciones que sobre este ha generado la Ley 1340 de 2009, que por su parte disponen:

En los términos de la Ley 155 de 1959 y del presente Decreto, están prohibidas las conductas que afecten la libre competencia en los mercados, las cuales, en los términos del Código Civil, se consideran de objeto ilícito.

[Inciso adicionado por el artículo 2 de la Ley 1340 de 2009]: Las disposiciones sobre protección de la competencia abarcan lo relativo a prácticas comerciales restrictivas, esto es acuerdos, actos y abusos de posición de dominio, y el régimen de integraciones empresariales. Lo dispuesto en las normas sobre protección de la competencia se aplicará respecto de todo aquel que desarrolle una actividad económica o afecte o pueda afectar ese desarrollo, independientemente de su forma o naturaleza jurídica y en relación con las conductas que tengan o puedan tener efectos total o parcialmente en los mercados nacionales, cualquiera sea la actividad o sector económico.

En tal sentido, la disposición normativa del artículo 46 del Decreto 2153 de 1992 corrobora y reafirma la constitución de la cartelización como tipo de prácticas restrictivas de la competencia, estableciendo por su parte que la celebración de cualquier 
tipo de acuerdos de los prohibidos por la normatividad aquí analizada, adolecen de validez por carecer de objeto lícito en los términos del artículo 1502 del Código Civil.

Sin embargo, es la Ley 1340 de 2009 la que integra a la tipología de las prácticas restrictivas de la competencia, por un lado, los actos restrictivos - que como se explicará a continuación no suponen la celebración de acuerdos con otros agentes del mercado sino que suponen una conducta individual del agente económico-y por otro lado, las conductas de abuso de la posición de dominio en el mercado.

De esta manera, resulta pertinente acudir a las definiciones previstas en el artículo 45 del Decreto 2153 de 1992 para establecer el concepto de los tipos de prácticas restrictivas de la competencia existentes en el ordenamiento jurídico colombiano, aclarando que, conforme al artículo citado, constituyen prácticas las conductas restrictivas de la competencia, vale decir, los actos y acuerdos que atenten contra este derecho constitucional económico, así como el abuso de la posición de dominio proscrito desde la disposición contenida en el artículo 333 superior.

\subsection{El abuso de la posición de dominio}

Con respecto a la posición de dominio, el Decreto 2153 de 1992 establece que aquella supone la posibilidad de que un agente determine, de manera directa o indirecta, las condiciones de un mercado.

Frente a tal posición, es preciso aclarar que el ordenamiento jurídico colombiano no proscribe que un agente económico goce de una posición dominante en el mercado cuando esta ha sido obtenida a partir de las ventajas que el agente ofrece en el mismo mercado a los consumidores, sino que, por el contrario, el ordenamiento prohíbe el ejercicio abusivo de esta posición con miras a cercenar la libertad de competencia e incluso los derechos del consumidor, pues como lo establece el inciso cuarto del artículo 333 constitucional, "El Estado, por mandato de la ley, impedirá que se obstruya o se restrinja la libertad económica y evitará o controlará cualquier abuso que personas o empresas hagan de su posición dominante en el mercado nacional”. 
Con esta aclaración, ha precisado Velandia (2011) que:

El abuso de la posición de dominio trata un supuesto fáctico que tiene aplicación en mercados altamente concentrados en un solo agente económico, imponiéndole a este, mediante regulación mayores responsabilidades ${ }^{14} \mathrm{o}$ cargas por los riesgos a que queda expuesto un mercado debido a la dependencia hacia una empresa. Es decir, lo que pretenden las normas de competencia es que existan muchas empresas en un mercado, pero existen algunos mercados donde esto no ocurre por su propia estructura o por la eficiencia de una empresa que acabó con sus competidores, sin que sea ilegal que en un mercado exista posición dominante, sin embargo, dicha situación sí resulta riesgosa para una economía, y por tanto, mediante el poder interventor del Estado se imponen mayores límites al actuar de agentes que ostentan poder de dominio, prohibiéndose algunos comportamientos que en caso de ser adelantados por empresas sin posición de dominio no resultarían calificados como abusivos.

Conforme a lo anterior, el abuso de la posición de dominio debe ser una prioridad para el Estado, quien a través de la regulación económica debe impedirla imponiendo obligaciones mayores a los agentes económicos que la ostenten y, a través de las funciones de inspección, vigilancia y control, debe sancionar el incumplimiento de las mismas, incumplimiento que en el escenario de mercado constituye el abuso de la posición de dominio.

Sin embargo, se considera que el abuso de la posición de dominio no es verificable en el ámbito de los procesos de selección de contratistas del Estado, toda vez que la misma no se genera al interior de un proceso de selección de contratistas o, existiendo algún viso, es la misma regulación de la contratación la que impide su consolidación, pues el oferente con posición de dominio que participa en un proceso de contratación, lo único que pretende es utilizar de manera legítima las ventajas competitivas que el mercado le ha generado y por las cuales ha adquirido su posición de dominio.

$14 \mathrm{Al}$ respecto, se considera procedente hacer referencia a Sarmiento, Medina y Plazas (2017), para quienes "la mejor interpretación que se le puede brindar a un estudioso del derecho de dańos o de responsabilidad civil sobre la distinción entre el daño y el perjuicio está en que el daño, en sí mismo considerado, es la lesión al bien jurídico tutelado, mientras que el perjuicio es la afectación de ese bien jurídico tutelado en la realidad, el cual se caracteriza por ser cuantificable ya sea en su valor material o en su valor inmaterial, medido por medio de la intensidad del daño sufrido" (p. 113). 
Tal afirmación tiene un argumento que la soporta: la legislación que regula la contratación estatal en Colombia ha reconocido la posibilidad de que los agentes económicos que tengan posición de dominio, participen en los procesos de selección de contratistas dispuestos en la legislación, pues no existe ninguna prohibición expresa para que ello ocurra, e incluso ha reconocido que existen bienes y servicios que solo pueden ser suministrados por un único agente económico, lo que por su parte permite inferir que la regulación entiende que en la dinámica de los mercados hay agentes con posición de dominio y que incluso, existen mercados que se desarrollan en dinámicas de monopolio.

En el primero de los casos (existencia de varios agentes entre los cuales uno o varios tienen posición de dominio en el mercado), la normatividad de la contratación dispone que se desarrollen los procesos previstos para la selección objetiva de los contratistas conforme a las ventajas y beneficios que cada uno, en competencia, pueda ofrecerle a la entidad estatal. Esto, por supuesto, en desarrollo y garantía de los principios de libre concurrencia, eficacia y eficiencia.

Si en este caso, alguno de los agentes económicos hace uso de su posición de dominio para eliminar del proceso a sus competidores con, por ejemplo, la baja de precios (ya sea por abuso de venta por debajo de costos, o abuso por mercados subsidiados), tal actuación tiene una limitación normativa que impide que se abuse de la posición de dominio, como lo es la disposición contenida en el artículo 2.2.1.1.2.2.4 del Decreto 1082 de 2015 que establece que:

\begin{abstract}
Si de acuerdo con la información obtenida por la Entidad Estatal en su deber de análisis de que trata el artículo 2.2.1.1.1.6.1 del presente decreto, el valor de una oferta parece artificialmente bajo, la Entidad Estatal debe requerir al oferente para que explique las razones que sustentan el valor ofrecido. Analizadas las explicaciones, el comité evaluador de que trata el artículo anterior, o quien haga la evaluación de las ofertas, debe recomendar, rechazar la oferta o continuar con el análisis de la misma en la evaluación de las ofertas.
\end{abstract}

Cuando el valor de la oferta sobre la cual la Entidad Estatal tuvo dudas sobre su valor, responde a circunstancias objetivas del oferente y de su oferta que no ponen en riesgo el cumplimiento del contrato si este es adjudicado a tal oferta, la Entidad Estatal debe continuar con su análisis en el proceso de evaluación de ofertas. 
En la subasta inversa esta disposición es aplicable sobre el precio obtenido al final de la misma.

En tal sentido, la baja de precios injustificada derivada del abuso de posición de dominio de un oferente en un proceso de contratación, da lugar al rechazo de su oferta, al consolidarse la figura de los precios artificialmente bajos, por lo que en tal caso, no se puede afirmar que el abuso de la posición de dominio sea una práctica restrictiva de la competencia que interfiera en los procesos de contratación estatal, pues tal disposición normativa impide que se configure el abuso de la posición dominante.

Conforme a lo anterior, ha de reiterarse que la baja de precios debe ser injustificada para que opere el rechazo de la oferta, lo que por su parte implica que, si la baja de precios se encuentra fundamentada en una ventaja competitiva legítima, la oferta debe ser evaluada conforme a las disposiciones normativas que regulan la materia. En otras palabras, cuando se logre determinar que la baja de precios obedece a la venta por debajo de costos, o a la existencia de mercados subsidiados, no existiría justificación legítima, pues tales conductas corresponden al ejercicio abusivo de la posición dominante de un agente en el mercado, y la oferta debe ser rechazada, lo que por su parte implica que, ante tal situación, las entidades estatales deben poseer un equipo suficientemente idóneo para lograr identificar tales conductas.

Sin embargo, bajo la existencia de casos en los que la entidad no perciba la ejecución de una conducta abusiva por la posición de dominio que ostente algún oferente, son los demás oferentes los llamados a evidenciarla a través de los mecanismos dispuestos en la legislación para la controversia de los informes de evaluación dentro de los procesos de selección, con el fin de que la entidad los analice y tome una determinación.

Por lo aquí expuesto, se considera que el abuso de la posición de dominio difícilmente puede superar un proceso de selección de contratistas del Estado, y por lo mismo, difícilmente la Superintendencia de Industria y Comercio podría estudiar, en sede de inspección, vigilancia y control, la comisión de una conducta abusiva en el marco de un proceso de contratación.

De otro lado, otros casos de abuso de posición de dominio como las ventas atadas o el abuso por discriminación, no son aplicables al ámbito de la contratación estatal, 
por cuanto en los procesos de selección de contratistas del Estado, es la entidad estatal la que impone las condiciones de la compra o de la prestación de los servicios requeridos, y no el oferente, como suele suceder en las relaciones económicas privadas.

En el segundo de los casos (contratación ante la inexistencia de pluralidad de oferentes), el ordenamiento ha permitido que las entidades del Estado contraten de manera directa con el único agente económico que suministre el bien o preste el servicio requerido. En tal caso, no podría hablarse de abuso de posición de dominio, pues la misma solamente se configura ante la pluralidad de agentes que produzcan o presten un mismo bien o servicio.

Lo que permite solucionar la disposición contenida en el artículo 2.2.1.2.1.4.8 del Decreto 1082 de 2015 es que, ante la certeza de la existencia de un monopolio, el Estado pueda contratar con este sin la apertura de un proceso licitatorio, vale decir, de manera directa, pues:

\begin{abstract}
Si hay certeza que el bien, servicio u obra que la entidad requiere solo puede ser realizado por una persona que existe en el mercado, no hay necesidad de convocar procesos de selección que se sabe de antemano serán inoficiosos [...]. La identificación acerca de la inexistencia de más de un proponente es el resultado de los estudios y análisis que debe efectuar la entidad durante la fase previa o preparatoria, tal como de manera expresa lo reconoce dicha norma (Dávila, 2016, p. 506).
\end{abstract}

\title{
3.2 Los actos restrictivos de la competencia
}

Con respecto a los actos, el artículo 45 del Decreto 2153 de 1992 establece que un acto lo constituye cualquier comportamiento de los agentes económicos, y en relación con los actos restrictivos de la libre competencia económica, Velandia (2011) entiende que con estos:

[...] se reprimen comportamientos unilaterales independientemente del grado de concentración del agente económico. Es decir, no son una norma con sujeto destinatario específico, como el abuso de la posición de dominio. Son conductas desarrolladas por una sola empresa cuyo comportamiento genera imperfecciones, generalmente de tipo vertical, por tanto están usualmente presentes en las relaciones entre productor y distribuidor y limitan el actuar de estos (p. 107). 
Un acto resulta ser entonces, una conducta ejecutada por un agente económico que cercena la libertad de competencia, no por constituir barreras a través de acuerdos con otros agentes — como en el caso de los acuerdos - o por ejecutar conductas que se derivan de la posición de dominio que se ostenta en el mercado, sino que pretenden cercenar el acceso al mercado de agentes cuya actividad económica se encuentra, generalmente, en la misma cadena de producción o distribución y por lo mismo requiere de la actividad del primero para el desarrollo de su actividad económica, o que pretenden cercenar los derechos del consumidor final del bien producido o del servicio prestado.

En tal sentido, el artículo 48 del Decreto 2153 de 1992, ha dispuesto que constituyen actos restrictivos de la competencia, los siguientes:

1. Infringir las normas sobre publicidad contenidas en el estatuto de protección al consumidor.

2. Influenciar a una empresa para que incremente los precios de sus productos o servicios o para que desista de su intención de rebajar los precios.

3. Negarse a vender o prestar servicios a una empresa o discriminar en contra de la misma cuando ello pueda entenderse como una retaliación a su política de precios.

Con fundamento en lo aquí descrito, puede afirmarse que los actos restrictivos de la competencia, al ser conductas unilaterales de agentes económicos tendientes a cercenar la participación de otros agentes en un determinado mercado (competencia en el mercado), tampoco son aplicables al ámbito de la contratación estatal, por las razones que a continuación se consideran:

Primero. Las normas de protección al consumidor en Colombia parten de un supuesto fundamental: el consumidor ha ostentado históricamente un papel de dominado en las relaciones de consumo, en tanto que el productor o distribuidor ostenta una posición de dominio. Por lo anterior, las normas de protección del consumidor fueron expedidas con la finalidad de garantizar los derechos del sujeto más débil en la relación de consumo. 
En el ámbito de los procesos de contratación, no se puede afirmar que el Estado ostente una posición de debilidad frente al oferente que participa de los procesos de selección que este convoca, ni mucho menos que existan normas de publicidad en relación con las ofertas presentadas por los proponentes, pues en este caso, es la entidad estatal misma la que fija los contenidos generales a los cuales debe sujetarse la oferta, y el proponente es quien decide si asume tales condiciones y por lo mismo si presenta su oferta, obligándose a cumplir con las prescripciones que en la misma le ofrece a la entidad convocante.

Segundo. El oferente no puede influenciar a la entidad para incrementar o reducir los precios sobre los que fundamenta los presupuestos en cada uno de los procesos de contratación que adelanta, toda vez que la entidad toma tales precios de los correspondientes estudios del sector, conforme a la obligación contenida en el artículo 2.2.1.1.1.6.1 del Decreto 1082 de 2015 que corresponde a un deber propio del principio de planeación. Sin embargo, lo que sí puede hacer el oferente -más allá de presionar a la entidad para que cambie sus precios a la alta o a la baja- es identificar las falencias que la entidad haya podido cometer en la elaboración del presupuesto, y hacérselas saber a través de las observaciones a los distintos documentos del proceso, conforme a las etapas previstas para tal fin en cada uno de los procesos de selección, sin que esto pueda considerarse como una presión para la modificación de los precios.

Tercero. El oferente no puede negarse a vender el producto contratado por la entidad estatal pues, como ya se anotó anteriormente en el presente trabajo, por un lado el adjudicatario de un contrato no puede negarse injustificadamente a la suscripción del mismo, so pena de recibir las sanciones previstas en la legislación, y por el otro, el contratante no puede incumplir las cláusulas contractuales, so pena de la aplicación de sanciones o incluso de cláusulas exorbitantes como la terminación unilateral o la declaratoria de caducidad del contrato, de acuerdo con lo dispuesto en los artículos 17 y 18 de la Ley 80 de 1993.

\subsection{Acuerdos restrictivos de la competencia}

En relación con los acuerdos restrictivos de la competencia, el numeral primero del artículo ya citado establece que aquellos los constituye "todo contrato, convenio, 
concertación, práctica concertada o conscientemente paralela entre dos o más empresas", comportamientos que son explicados por Velandia (2011) de la siguiente forma:

Los carteles agrupan la prohibición de comportamientos arreglados, adelantados por dos o más empresas encaminadas a alterar la competencia, bien sea porque pretenden excluir a un competidor o porque se busca adelantar una colusión entre ellos para dejar de competir. Se trata de comportamientos arreglados entre empresas que se encuentran dentro de un mismo mercado relevante. Entre ellas arreglan o falsean la obligación de competir (p. 106).

Con lo anterior, cualquier arreglo contenido o no en un acuerdo formal, efectuado entre competidores de un mercado relevante, constituye una conducta restrictiva de la libre competencia económica y en tal sentido debe ser investigada y sancionada por la Superintendencia de Industria y Comercio en el marco de la garantía constitucional al debido proceso.

Desde esta perspectiva, conforme lo expresa Velandia, la cartelización o celebración de acuerdos formales o informales, tendientes a restringir la participación de otros agentes en el mercado, puede evidenciarse en dos grupos de situaciones, cada una de ellas con un abanico de conductas que las pueden configurar: de un lado, la concertación, acuerdo o práctica conscientemente paralela entre agentes económicos para sustraer a otros competidores del mercado, y del otro, el acuerdo o concertación entre agentes para dejar de competir y generar imperfecciones en el mercado. En el primero de los casos, se tratará de cualquiera de los acuerdos restrictivos de la competencia previstos en el artículo 47 del Decreto 2153 de 1992, exceptuando el contenido en el numeral 9, y en el segundo, de acuerdos colusorios dispuestos en el numeral 9 del artículo indicado.

Por la estructura misma de las conductas previstas en los numerales 1 al 8 y 10 del artículo 47 citado, se puede afirmar que las mismas no constituyen acuerdos restrictivos de la competencia aplicables al ámbito de la contratación estatal, toda vez que por la regulación específica de la contratación pública no es posible que los oferentes y las entidades fijen directa o indirectamente los precios, toda vez que los mismos han de corresponder — como ya se anotó— a los resultados de un estudio del sector; 
tampoco se pueden concertar condiciones de venta o de comercialización discriminatorias frente a terceros, pues en el ámbito de la contratación estatal es la entidad la que determina las condiciones de venta del bien o servicio requerido a través de los respectivos pliegos de condiciones; no es aplicable la repartición de mercados ni la asignación o repartición de cuotas de producción o limitación de fuentes de abastecimiento o de desarrollos técnicos, toda vez que los procesos de selección convocados por las entidades del Estado no están dirigidos a satisfacer un mercado específico distinto al que crea la misma entidad estatal, sino por el contrario, a la satisfacción de las necesidades de la entidad. Tampoco el oferente puede subordinar a la adquisición de un producto determinado la asunción de obligaciones adicionales, toda vez que, como ya se ha mencionado, en los procesos de contratación pública quien impone las condiciones de la compra es la entidad estatal en el marco de un proceso de selección objetiva. Tampoco la autoridad estatal mediante sus procesos de selección impone a los oferentes el hecho de abstenerse de producir determinados bienes o servicios o afectar sus niveles de producción, ni mucho menos impone a terceros el acceso a mercados o canales de producción. Por lo anterior, se puede afirmar que tales conductas constitutivas de acuerdos restrictivos son propias del ámbito de las relaciones económicas privadas.

Sin embargo, sí existen entre los acuerdos restrictivos de la competencia tipificados por la norma citada, unas prácticas que se evidencian en las actuaciones de los oferentes que han sido estudiadas con profundidad por la Superintendencia de Industria y Comercio, y que además de afectar los procesos mismos de contratación, impactan de manera irrestricta la libre competencia económica y, como ya se dijo, el principio de libre concurrencia en los procesos de selección de contratistas del Estado.

Tales conductas son las tipificadas en el numeral 9 del artículo 47 del Decreto 2153 de 1992, que estatuye como acuerdos restrictivos de la competencia "[1] os que tengan por objeto la colusión en las licitaciones o concursos o los que tengan como efecto la distribución de adjudicaciones de contratos, distribución de concursos o fijación de términos de las propuestas", los cuales son conocidos como prácticas colusorias, que se procederán a explicar brevemente. 
De una lectura superflua de la prescripción contenida en el numeral noveno del artículo 47 del Decreto 2153 de 1992, se puede inferir lo siguiente: son acuerdos restrictivos de la competencia que pueden ser ejecutados por los oferentes en el marco de procesos de selección de contratistas del Estado, de un lado, aquellos acuerdos colusorios entre oferentes o, del otro, aquellos acuerdos entre estos y miembros de las entidades estatales, que tengan como efecto la distribución de adjudicaciones de licitaciones o concursos o la fijación de términos de las propuestas, todas estas denominadas de manera genérica por la doctrina y la normatividad vigente como "prácticas colusorias".

\subsubsection{Los acuerdos colusorios como prácticas restrictivas de la competencia en el marco de procesos de selección de contratistas del Estado}

Hablar de derecho a la libre competencia, de principio de libre concurrencia y de prácticas colusorias en el marco de la contratación estatal colombiana, parte de suponer que el Estado, al contratar bienes o servicios para suplir sus necesidades y las de sus asociados, crea mercados frente a los cuales los particulares compiten a través de sus ofertas ${ }^{15}$.

Si se entiende entonces que la presencia de necesidades de las entidades estatales y los consecuentes procesos de contratación que estas convocan para la satisfacción de las mismas constituyen mercados en sí mismos, lo que se espera de ellos es que se constituyan como mercados sin barreras de acceso injustificadas, en los que los interesados en participar en ellos ofrezcan sus mejores ventajas y derivado de las mismas tengan la facultad de contratar con el Estado el bien o servicio requerido, o en otras palabras, lo que se espera de ellos es que se garantice el derecho constitucional a la libre competencia (por el mercado) como lo reconoce y garantiza el artículo 333 constitucional, y el principio de la libre concurrencia como lo certifica la normatividad que rige la contratación estatal en Colombia.

15 Así lo reconoce Ossa (2014), al afirmar que: "[...] cuando la administración, de acuerdo con su necesidad, llama a los particulares a que participen en un proceso de licitación pública o selección abreviada, lo que hace en últimas es crear un mercado, y en consecuencia, invitar a los mismos agentes a que compitan por ese mercado creado por el Estado, es una competencia por hacerse a un monopolio al final del proceso de licitación o selección" (p. 237). 
En tal sentido, la colusión o prácticas colusorias se identifican como aquellas prácticas restrictivas de la competencia que se generan al interior de un proceso de contratación del Estado, vale decir, en la generación de un mercado específico por el cual los oferentes compiten para prestar los bienes o servicios en él requeridos, y que generan graves consecuencias como las que a continuación se indican:

[...] la colusión en los procesos de selección con el Estado conlleva diversos efectos negativos en varios agentes, entre los que cabe resaltar los siguientes: (i) otros proponentes al limitarles la competencia y la participación en un proceso de selección justo y regidos por los principios de igualdad de oportunidades y de transparencia, (ii) el Estado, por los costos monetarios y de transacción que representa la presencia de proponentes no idóneos en sus procesos de selección, (iii) el mercado, porque se reduce la competencia, se generan asimetrías de información entre los proponentes e incluso se pueden elevar los precios de los bienes y servicios ofrecidos o reducirse su calidad y, (iv) la comunidad en general, por cuanto se afecta negativamente el bienestar social al darse una pérdida irrecuperable de eficiencia en el mercado por el aumento injustificado de utilidades percibidas por los participantes coludidos (Superintendencia de Industria y Comercio, junio 28 de 2012).

De otro lado, es preciso establecer que, por los efectos que generan los acuerdos colusorios, el ordenamiento jurídico colombiano, a partir de la expedición del Estatuto Anticorrupción ${ }^{16}$ - Ley 1474 de 2011—, ha elevado esta práctica a la categoría de delito, como lo prescribe el artículo 27 de la norma citada que establece que:

La Ley 599 de 2000 tendrá un artículo 410A, el cual quedará así:

El que en un proceso de licitación pública, subasta pública, selección abreviada o concurso se concertare con otro con el fin de alterar ilícitamente el procedimiento contractual, incurrirá en prisión de seis (6) a doce (12) años y multa de doscientos (200) a mil (1.000) salarios mínimos legales mensuales vigentes e inhabilidad para contratar con entidades estatales por ocho (8) años.

16 Es importante resaltar que: "Según un informe de Transparencia Internacional, Colombia se encuentra en el puesto 90 entre 176 países que denotan un alto grado de corrupción y a nivel latinoamericano somos superados por países como Venezuela, Nicaragua y México. El Programa de Naciones Unidas para el Desarrollo menciona en su 'Manual de Buenas Prácticas de Transparencia en la Gestión Contractual', que el $91 \%$ de los empresarios percibe un grado de corrupción en cuanto a lo que tiene que ver con los procesos de contratación” (Nieves, 2017, p. 13). 
Sin embargo, aunque se ha hecho una breve reseña sobre la importancia de la libre competencia en los procesos de contratación estatal y sobre el carácter restrictivo que los acuerdos colusorios le imprimen a la libre concurrencia, hasta el momento no se ha hecho esfuerzo alguno por identificar una definición precisa de lo que el ordenamiento jurídico colombiano ha entendido por colusión.

Para ello, resulta pertinente traer a colación la definición que la Superintendencia de Industria y Comercio, como órgano encargado de la defensa y garantía de la libre competencia, ha considerado en relación con la colusión:

[...] la acción o efecto de coludir, es decir, el hecho o circunstancia de pactar en contra de un tercero o a una de las partes. Entonces, cuando los oferentes coluden entre sí para distorsionar el proceso licitatorio, la adjudicación sería el producto de un acuerdo ilícito que contraría la libre competencia.

En este sentido, cuando se realizan acuerdos entre los proponentes para no competir, para distribuirse adjudicaciones de contratos y concursos o fijar los términos de las propuestas, se está incurriendo en una práctica contraria a la libre competencia, tal y como lo describe el numeral 9 del artículo 47 del Decreto 2153 de 1992 [...] (Superintendencia de Industria y Comercio, septiembre 27 de 2017).

De esta manera, la colusión comprende un acuerdo de voluntades, o —en los términos del numeral primero del artículo 45 del Decreto 2153 - todo contrato, convenio, práctica concertada o conscientemente paralela entre dos o más oferentes que tenga por objeto sustraer la competencia por el mercado en un proceso de selección, o que tenga por objeto o como efecto distribuir adjudicaciones de contratos, distribuir concursos o fijar los términos de las propuestas para así destruir la libre competencia al interior de un proceso de selección determinado.

De esta breve descripción se puede reconocer, como lo afirma Velandia (2011), que la colusión:

No es cualquier conducta [...] reprochada, pues no debe olvidarse que estamos en presencia de un tema típico de derecho económico, en donde es menester verificar si la participación de los interesados se está viendo afectada por la conducta adelantada por otros. En este sentido, el pacto debe ser esencialmente ese, aquel que tenga la intención 
de no permitir la libre entrada o condiciones que defrauden a los interesados. Por tanto, el punto relevante recae en el móvil que debe observarse en la colusión, el cual debe consistir en conductas que no permiten el acceso o libre escogencia en el concurso o en la licitación (p. 157).

Desde esta perspectiva, al reconocer los efectos nocivos que las prácticas colusorias acarrean en relación con el derecho constitucional económico a la libre competencia, resulta pertinente culminar el presente acápite con una referencia a los momentos de los procesos de contratación en los que, según la Superintendencia de Industria y Comercio, pueden verificarse prácticas colusorias:

[...] las conductas colusorias pueden darse (i) durante la etapa de elaboración de los pliegos de condiciones cuando existe intercambio de información entre los funcionarios de la entidad y los futuros proponentes, (ii) durante la presentación de ofertas, presentando ofertas que no tienen posibilidad de obtener adjudicación, acordando la abstención de uno o más competidores o el retiro de las ofertas, acordando turnos para ganar o repartiéndose el mercado o las zonas geográficas y, (iii) durante la ejecución del contrato, recurriendo a técnicas como la subcontratación, para vincular a los demás postulantes que no fueron escogidos o la utilización de la figura de la cesión del contrato, por ejemplo (Superintendencia de Industria y Comercio, septiembre 27 de 2017).

Con lo anterior es dable precisar que la colusión, como práctica restrictiva de la competencia, solamente puede ser atribuida a los agentes económicos particulares que en ella incurran, en tanto que como delito previsto en el artículo 401A de la Ley 599 de 2000, adicionado por el artículo 27 de la Ley 1474 de 2011, también puede ser imputado al funcionario público que participe en el acuerdo colusorio, a quien además se le pueden imputar los delitos de interés indebido en la celebración de contratos y el de celebración de contratos sin el lleno de los requisitos legales, si fuere el caso.

\section{Algunas prácticas COlUSORIAS IDENTIFICADAS POR LA SIC EN EL MARCO DE PROCESOS DE CONTRATACIÓN ESTATAL}

Una vez identificados los elementos esenciales del concepto de prácticas colusorias en el ámbito de la contratación estatal, resulta pertinente hacer alusión a algunos de los casos estudiados por la Superintendencia de Industria y Comercio durante el último 
año, en los que tal entidad encontró fundamento para formular pliego de cargos o incluso sancionar o tomar medidas contra algunos agentes económicos por evidenciar acuerdos restrictivos en la participación de procesos de selección de contratistas del Estado. Esto con el fin de ilustrar o ejemplificar algunas de las formas como se concretan tales prácticas en la realidad de los procesos de contratación del Estado.

Tal objetivo se pretende lograr a partir de un breve análisis de algunas de las resoluciones emitidas por la Superintendencia de Industria y Comercio escogidas aleatoriamente, a través de las cuales estudió la comisión de prácticas restrictivas por parte de oferentes participantes de procesos de contratación estatal.

\subsection{Caso Proyectar Ingeniería S. A. S. y Desarrollamos Ingeniería S. A. S.: apertura de investigación y formulación de cargos}

En la Resolución No 70225 de 2016, la Superintendencia de Industria y Comercio decide abrir investigación y formular pliego de cargos por las prácticas comerciales restrictivas ejecutadas por las empresas Proyectar Ingeniería S. A. S. y Desarrollamos Ingeniería S. A. S., teniendo en cuenta que, conforme a la queja presentada por el Ministerio de Cultura, se encontró que las mismas presuntamente elaboraron conjuntamente sus propuestas, pues esta última entidad, en la evaluación de cada una de estas, encontró que en la propuesta de la primera se anexó el documento que determina la calidad de mipyme o pyme de la segunda, y en la oferta de la segunda se anexó el documento que determina la calidad de mipyme o pyme de la primera.

Conforme con la queja antes descrita, la Superintendencia de Industria y Comercio logró determinar que, aunque las empresas investigadas eran representadas legalmente por personas distintas, ellas sí poseían el mismo contador público y el mismo revisor fiscal, y que adicionalmente a lo anterior las dos empresas certificaron experiencia dentro del proceso desarrollado por el Ministerio de Cultura con contratos celebrados con las mismas empresas, además de presentar ofertas con similitudes en forma y escritura y presentar pólizas expedidas por el mismo intermediario de seguros y en la misma fecha, entre otras particularidades que permiten inferir que las propuestas fueron elaboradas conjuntamente. 
De esta manera, al identificar la posible comisión de una práctica colusoria al interior de un proceso de selección de contratistas del Estado, la SIC determinó en el caso concreto que:

[...] el mercado para los casos de colusión nace de la interacción entre la demanda representada en la necesidad que tiene la entidad contratante y que la lleva a actuar como comprador en busca de ofrecimientos en las mejores condiciones para satisfacerla y la oferta de bienes y servicios de los agentes económicos conocidos como proponentes que pretenden ser adjudicatarios del proceso.

Las condiciones especiales de este mercado lo caracterizan como: i) temporal por cuanto nace con la intención de la entidad contratante y finaliza con la terminación anormal del proceso de selección o con la liquidación del contrato en que deviene, ii) excluyente por cuanto una vez definido no resulta procedente la inclusión de nuevos agentes al mismo (barrera a la entrada), excluyendo de esta forma cualquier futura competencia por la adjudicación del contrato y, por último, es iii) independiente por cuanto el escenario de contienda que se genera es ajeno a los demás mercados en los que los agentes participantes pueden competir (Superintendencia de Industria y Comercio, octubre 20 de 2017).

Conforme con lo anterior, al encontrar la presunta comisión de una práctica comercial restrictiva, la Superintendencia de Industria y Comercio decidió abrir investigación y formular cargos a las empresas investigadas por afectar el derecho constitucional a la libre competencia en el mercado específico del proceso de selección en el que participaron.

\subsection{Caso Concesionaria Ruta del Sol y Agencia Nacional de Infraestructura (sobornos Odebrecht): imposición de medidas cautelares}

El análisis de la Resolución No 5216 de 2017, expedida por la Superintendencia de Industria y Comercio, resulta de importante relevancia para la identificación de prácticas colusorias ejecutadas en el marco de procesos de contratación estatal, teniendo en cuenta que en esta se imponen medidas cautelares sobre un proceso de contratación, con fundamento en prácticas concertadas entre oferentes y entidades 
del Estado, situación que corrobora la proposición previamente formulada en el presente trabajo conforme a la cual las prácticas colusorias no solamente se pueden presentar entre oferentes de los procesos de contratación, sino incluso entre estos y las entidades estatales.

En el presente caso, la Superintendencia de Industria y Comercio analizó las conductas anticompetitivas realizadas por los integrantes del oferente adjudicatario del contrato de concesión a través del cual se concesionó la construcción del Sector 2 de la denominada Ruta del Sol, el cual fue adjudicado a la Estructura Social Promesa de Sociedad Futura Concesionaria Ruta del Sol S. A. S., conformada por las empresas Constructora Norberto Odebrecht S. A., Odebrecht Investimentos em Infraestructura Ltda., Estudios y Proyectos del Sol S. A. S., y CSS Constructores S. A., que resultó constituyendo la Concesionaria Ruta del Sol S. A. S.

Conforme a lo investigado por la SIC, se logró evidenciar que:

[...] con base en la información recolectada hasta el momento $-\mathrm{y}$ sin perjuicio de que durante el transcurso de la eventual investigación administrativa que adelante esta Entidad se encuentren evidencias que den cuenta de otras conductas presuntamente anticompetitivas-, dicha adjudicación habría sido resultado del direccionamiento del proceso de licitación por parte de funcionarios de la entidad contratante - INCO(hoy ANI), a cambio de un soborno pagado por algunos de quienes hicieron parte del proponente ganador, con lo que se habrían limitado las condiciones de competencia en el referido proceso y asegurando el resultado de la adjudicación (Superintendencia de Industria y Comercio, febrero 16 de 2017).

Tal afirmación fue emitida como resultado de las investigaciones realizadas por las entidades colombianas y derivadas de la información publicada por el Departamento de Justicia de los Estados Unidos de América, en la cual se divulgó la declaratoria de culpabilidad de la empresa Odebrecht frente a la puesta en funcionamiento de una estructura criminal en la que se pagaron sobornos en millones de dólares, a las autoridades de distintos países —entre los cuales se encontraba Colombia- para la obtención de millonarios negocios. 
De esta manera, según lo emitido en el informe del Departamento de Justicia de los Estados Unidos y de las investigaciones dirigidas por la Fiscalía General de la Nación colombiana, se logró determinar que:

[...] la firma Odebrecht efectuó pagos para obtener varios contratos de obra ${ }^{17}$ en Colombia y que un primer ilícito por USD6.5 millones, se llevó a cabo para lograr la adjudicación de la concesión, por el Instituto Nacional de Concesiones (INCO), dirigido en calidad de encargado por Gabriel García Morales, entonces viceministro de Transporte de la época, del tramo dos de la Ruta del Sol [...] contrato que fue adjudicado en diciembre de 2009 y firmado en enero de 2010 (Superintendencia de Industria y Comercio, febrero 16 de 2017).

Según la investigación realizada por la SIC, se evidencia información en la que el señor García Morales, presuntamente asesoró a funcionarios de la empresa adjudicataria durante el proceso licitatorio a través del cual resultaría adjudicado el contrato de concesión para la construcción del tramo dos de la Ruta del Sol, y direccionó el proceso licitatorio con el fin de favorecer la propuesta presentada por esta empresa y de esta manera configuró una concertación que atentó contra la libre competencia.

Teniendo en cuenta entonces que, de un lado, el proponente que resultó adjudicatario de la licitación, aceptó ante la justicia de los Estados Unidos la comisión del ilícito y que, de la otra, el exviceministro de Transporte Gabriel Ignacio García Morales aceptó los delitos imputados por la Fiscalía General de la Nación referidos a los sobornos recibidos para el direccionamiento y adjudicación del proceso licitatorio a través del cual se concesionaría la construcción del tramo dos de la Ruta del Sol, la Superintendencia de Industria y Comercio encontró que el accionar del oferente y del funcionario constituyó una conducta atentatoria del derecho constitucional a la libre competencia, al considerar que:

17 Es necesario resaltar que "Para un país en vía de desarrollo como Colombia la contratación de obras tendientes a la construcción y operación de vías de comunicación debe ser una actividad dinámica. Es por lo anterior que desde la década de los noventa se empezó a acudir a la participación de inversionistas particulares quienes, mediante la modalidad de concesión, se encargaron de la construcción y operación de vías en diferentes regiones del país, lo que hizo necesario construir un marco institucional y jurídico que desde el comienzo debió adaptarse a las definiciones establecidas en la Ley 80 de 1993” (Paz y Blanco, 2015, p. 171). 
[...] considerando que los recursos con los cuales se financian los contratos adjudicados por el Estado (compras públicas de bienes y servicios) son de carácter público, las consecuencias de una restricción indebida de la competencia en el marco de estos procesos de selección contractual son particularmente graves (mucho más graves) pues se presentan sobrecostos y pérdidas irrecuperables de recursos públicos que terminan por desfinanciar otras inversiones que el Estado debe realizar, lo cual a su vez representa lesiones importantes en términos de bienestar social, desarrollo económico y eficiencia económica. $[\ldots]$

Así, el proceso competitivo y el logro de sus consecuentes eficiencias en un proceso de selección contractual adelantado por el Estado dependerán de que la elección del ganador se realice con sujeción a las reglas de la libre competencia económica. Esto es, que cada uno de los proponentes, con el propósito de maximizar sus beneficios, concurse y realice su mayor esfuerzo por resultar ganador, lo cual implicará la presentación de una oferta que pueda superar a la de sus competidores dada su relación de costo-beneficio para la entidad contratante. En la medida en que cada oferente realice este mismo proceso de manera independiente, el Estado terminará seleccionando la mejor oferta. En estos casos, el Estado hace las veces de consumidor y como cualquier consumidor tiene el derecho de recibir ofertas con los mejores precios y condiciones, y por tratarse de compras públicas (dineros públicos), el Estado tiene la obligación de escoger la mejor oferta, y no cualquier oferta.

En línea con lo anterior, la libre competencia económica en un proceso de selección contractual se ve falseada por la manipulación de su resultado, de forma tal que el adjudicatario se hace al contrato objetivo sin someterse a un proceso competitivo sino por cuenta de maniobras de carácter ilícito. Tales estrategias anticompetitivas habitualmente se presentan de dos formas: (i) acuerdos entre oferentes — hay muchas modalidades y tipologías- y, (ii) corrupción de funcionarios públicos, sin perjuicio de otro tipo de prácticas consideradas también anticompetitivas (Superintendencia de Industria y Comercio, febrero 16 de 2017).

Teniendo en cuenta lo anterior, y con fundamento en la facultad dispuesta en el numeral 11 del artículo 4 del Decreto 2153 de 1992 que le permite imponer medidas cautelares en el marco de procesos de investigación de prácticas comerciales restrictivas, la Superintendencia de Industria y Comercio decretó la medida cautelar de cesación o suspensión de los efectos de las conductas atentatorias contra este derecho cometidas por parte del Instituto Nacional de Concesiones — hoy Agencia Nacional 
de Infraestructura (ANI) - y la Concesionaria Ruta del Sol S. A. S., y como consecuencia de lo anterior, y con el fin de restablecer la libre competencia económica, ordenar a la ANI dar por terminado de manera inmediata el contrato de concesión No 001 del 14 de enero de 2010 junto con sus modificaciones, adiciones y otrosíes, suscrito con la concesionaria Ruta del Sol S. A. S.

La anterior decisión fue emitida por la SIC, con fundamento en el deber dispuesto en el inciso segundo del artículo 45 de la Ley 80 de 1993 que establece que el jefe o representante legal de la entidad respectiva debe dar por terminado el contrato celebrado cuando el mismo esté viciado de nulidad absoluta, por: i) haberse celebrado con personas incursas en causales de inhabilidad o incompatibilidad previstas en la Constitución y la ley, ii) haberse celebrado contra expresa prohibición constitucional o legal y, iii) se hayan declarado nulos los actos administrativos en que se fundamente.

\subsection{Caso San Martín - Consequín: apertura de investigación y formulación de cargos}

La primera referencia corresponderá a la Resolución No 18645 de 27 de abril de 2017, a través de la cual, la Superintendencia de Industria y Comercio decidió abrir una investigación y formular pliego de cargos a las empresas Seguridad San Martín Ltda. y Cosequín Ltda., —ambas instituidas para la prestación del servicio de seguridad privada - por considerar que su conducta constituyó la celebración de un acuerdo colusorio en el marco de procesos de contratación estatal.

La apertura de la investigación y la formulación de cargos tuvo su fundamento en la existencia de un esquema de coordinación y colaboración anticompetitivo ejecutado por los representantes legales de las empresas investigadas, que se evidenció en la participación de ambas empresas en diversos procesos de contratación de entidades estatales, en los que, conforme al material probatorio analizado por la entidad:

[...] es CONSEQUÍN quien se encarga de identificar los procesos de selección en los que CONSEQUÍN Y SAN MARTÍN reúnen las condiciones para participar de manera individual. Una vez identificados aquella compañía invita a SAN MARTÍN a participar dentro de los procesos como aparentes competidores, y en caso de que SAN MARTÍN acepte la invitación, es CONSEQUÍN quien se encarga de elaborar 
las ofertas para las dos compañías (Superintendencia de Industria y Comercio, abril 19 de 2017).

De otro lado, la Superintendencia también encontró elementos probatorios que determinaron cómo las empresas investigadas establecían comunicación para la preparación de sus ofertas económicas, en por lo menos ocho (8) procesos licitatorios, con el fin de que una de ellas eligiera la propuesta económica que podría resultar más favorable según los mecanismos de evaluación aplicables para cada caso, y de esta manera "tener una oportunidad más" de ganarse la adjudicación del contrato respectivo, y elementos probatorios en los que se evidenció la presentación de ofertas formalmente idénticas por parte de las empresas investigadas.

Conforme con lo anterior, al encontrarse que una de las empresas investigadas (Consequín Ltda.) se encargaba de invitar a la otra (San Martín Ltda.) a participar de varios procesos de selección de contratistas del Estado y que, en caso de aceptación de la segunda, era la primera quien se encargaba de estructurar todos los documentos técnicos, jurídicos y financieros de las dos propuestas, y de cobrar una comisión en caso de que la segunda fuese adjudicataria del contrato respectivo - entre otros aspectos que determinaron la existencia de prácticas coordinadas-, la Superintendencia de Industria y Comercio decidió abrir la correspondiente investigación, teniendo en cuenta que en conjunto con la OCDE ha identificado una serie de advertencias que determinan la comisión de una práctica colusoria (Superintendencia de Industria y Comercio, abril 19 de 2017), entre las que se encuentran:

- Se presentan cotizaciones similares para la elaboración de los estudios previos.

- Observaciones muy similares al proyecto de pliego de condiciones.

- Entrega de varias propuestas por parte de una misma persona.

- Similitud de errores en la propuesta.

- Formatos similares en las propuestas cuando no son provistos por la entidad.

- Datos, certificaciones y personal idéntico entre distintos proponentes. 
- Documentos presentados con números consecutivos o expedidos con poco tiempo de diferencia o simultáneamente.

- Observaciones similares al informe de evaluación de las propuestas.

- Subcontratación de proponentes rivales una vez adjudicado el contrato.

- El adjudicatario es el mismo a lo largo del tiempo en varios procesos.

- Potenciales proponentes que, teniendo la capacidad, no se presentan al proceso sin mediar razón.

- Retiro sistemático de proponentes al proceso.

- Proponentes que se presentan constantemente y nunca son adjudicatarios.

- Proponentes que dejan de presentarse en consorcios o uniones temporales que solían conformar, para ahora hacerlo de forma independiente.

- Ofertas muy diferentes en procesos de similares condiciones.

- Cambio de conducta de los habituales oferentes ante el ingreso de uno nuevo.

\section{ConClusiones}

- El derecho a la libre competencia económica en el ámbito de la contratación estatal colombiana encuentra un evidente desarrollo a partir de la institución del principio de libre concurrencia de oferentes, según el cual está proscrito cualquier tipo de discriminación para el acceso o participación en procesos de selección de contratistas del Estado, a la vez que posibilita la competencia y oposición entre los interesados en la contratación.

- La garantía de la libre concurrencia de oferentes en procesos de contratación del Estado, además de ser un principio derivado de la reglamentación de los procesos de contratación, también encuentra su fundamento en la 
proscripción de ejecución de acuerdos que restrinjan la libre competencia económica a partir de prácticas colusorias, según lo dispuesto en el numeral noveno del artículo 47 del Decreto 2153 de 1992, cuya garantía corresponde a la Superintendencia de Industria y Comercio.

- Las principales prácticas colusorias desarrolladas por los oferentes en procesos de contratación estatal en Colombia, están relacionadas con la celebración de acuerdos entre oferentes para la participación o no de los mismos en procesos licitatorios o concursos, acuerdos entre oferentes y funcionarios de las entidades del Estado para el direccionamiento de la adjudicación del respectivo contrato en los distintos procesos de selección, así como la presentación coordinada de ofertas de distintos oferentes para garantizar la adjudicación del respectivo contrato en uno u otro participante de los que celebraron el acuerdo, entre otras tantas conductas investigadas y sancionadas por la Superintendencia de Industria y Comercio.

\section{REFERENCIAS}

Arias, J. C. (2017). Colombia: del Estado social a la esquizofrenia constitucional. Revista Verba Iuris, 12(38), 63-79. Recuperado de file://C:/Users/Usuario/Downloads/1053Texto\%20del\%20art\%C3\%ADculo-1588-1-10-20170928.pdf

Barone, J. (2018). El deber de mitigar los daños por incumplimiento contractual. Estudio sobre su adopción en el derecho privado colombiano. Revista Verba Iuris, 13(39), 81-106. Recuperado de file://C:/Users/Usuario/Downloads/1319-Texto\%20del\%20art\%C3\% ADculo-1984-1-10-20180312\%20(1).pdf

Castro, J. (2018). Alcance del principio iura novit curia en la responsabilidad del Estado colombiano. Revista Via Inveniendi et Iudicandi, 13(1), 169-187. DOI: http://dx.doi. org/10.15332/s1909-0528.2018.0001.06. Recuperado de http://revistas.usantotomas. edu.co/index.php/viei/article/view/4270/4047

Consejo de Estado colombiano. (2007). Sala de lo Contencioso Administrativo. Sección Tercera. Expedientes No 24715, 25206, 25409, 24524, 27834, 25410, 26105, 28244 , 31447, Acumulados. C. P. Ruth Stella Correa Palacio, 3 de diciembre de 2007. 
Constitución Política colombiana. (1991). Asamblea Nacional Constituyente, Bogotá, Colombia, 6 de julio de 1991.

Corte Constitucional colombiana. (1995). Sentencia C-524. Sala Plena. M. P. Carlos Gaviria Díaz, 16 de noviembre de 1995.

Corte Constitucional colombiana. (2000). Sentencia C-727. Sala Plena. M. P. Vladimiro Naranjo Mesa, 21 de junio de 2000.

Corte Constitucional colombiana. (2001). Sentencia C-616. Sala Plena. M. P. Rodrigo Escobar Gil, 13 de junio de 2001.

Corte Constitucional colombiana. (2009). Sentencia C-713. Sala Plena. M. P. María Victoria Calle Correa, 7 de octubre de 2009.

Corte Constitucional colombiana. (2010). Sentencia C-228. Sala Plena. M. P. Luis Ernesto Vargas Silva, 24 de marzo de 2010.

Corte Constitucional colombiana. (2012). Sentencia C-570. Sala Plena. M. P. Jorge Ignacio Pretelt Chaljub, 18 de julio de 2012.

Corte Constitucional colombiana. (2017). Sentencia C-032. Sala Plena. M. P. Alberto Rojas Ríos, 25 de enero de 2017.

Correa, M. (2009). La libertad de empresa en el Estado social de derecho. Bogotá D. C., Colombia: Universidad Externado de Colombia.

Dávila, L. G. (2016). Régimen jurídico de la contratación estatal. Bogotá D. C., Colombia: Legis S. A.

Decreto No 2153. (1992). Por el cual se reestructura la Superintendencia de Industria y Comercio y se dictan otras disposiciones. Diario Oficial No 40.704 de la República de Colombia. Bogotá D. C., Colombia, 30 de diciembre de 1992.

Decreto No 4886. (2011). Por medio del cual se modifica la estructura de la Superintendencia de Industria y Comercio, se determinan las funciones de sus dependencias y se dictan otras disposiciones. Diario Oficial No 48.294 de la República de Colombia. Bogotá D. C., Colombia, 23 de diciembre de 2011. 
Decreto No 1082. (2015). Por medio del cual se expide el Decreto único reglamentario del sector administrativo de planeación nacional. Diario Oficial No 49.523 de la República de Colombia. Bogotá D. C., Colombia, 26 de mayo de 2015.

Gómez S., A. (2017). Elaboración del guion instruccional mediante la herramienta didáctica del recurso educativo digital. Revista Via Inveniendi et Iudicandi, 12(2), 149-180. DOI: http://dx.doi.org/10.15332/s1909-0528.2017.0002.06. Recuperado de http://revistas. usantotomas.edu.co/index.php/viei/article/view/3751/3713

Ley No 155. (1959). Por la cual se dictan algunas disposiciones sobre prácticas comerciales restrictivas. Diario Oficial No 30.138 de la República de Colombia. Bogotá D. C., Colombia, 24 de diciembre de 1959.

Ley No 80. (1993). Por la cual se expide el estatuto general de la contratación de la administración pública. Diario Oficial No 41.094 de la República de Colombia. Bogotá D. C., Colombia, 28 de octubre de 1993.

Ley No 489. (1998). Por la cual se dictan normas sobre la organización y funcionamiento de las entidades del orden nacional, se expiden las disposiciones, principios y reglas generales para el ejercicio de las atribuciones previstas en los numerales 15 y 16 del artículo 189 de la Constitución Política y se dictan otras disposiciones. Diario Oficial No 43.464 de la República de Colombia. Bogotá D. C., Colombia, 29 de diciembre de 1998.

Ley No 1340. (20099. Por medio de la cual se dictan normas en materia de protección de la competencia. Diario Oficial No 47.420 de la República de Colombia. Bogotá D. C., Colombia, 24 de julio de 2009.

Nieves-López, J. (2017). El principio de selección objetiva en la licitación pública: análisis desde la etapa precontractual. Revista Verba Iuris, 12(37), 13-24. Recuperado de file://C:/Users/Usuario/Downloads/1020-Texto\%20del\%20art\%C3\%ADculo1525-1-10-20170920.pdf

OCDE. (2014). Combatiendo la colusión en los procesos de contratación pública en Colombia. Informe del secretariado sobre el marco jurídico y las prácticas de contratación pública en Colombia. Organización para la Cooperación y el Desarrollo Económicos - OCDE. Recuperado de https://www.oecd.org/daf/competition/2014_Fighting\%20Bid\%20Rigging\%20Colombia_SPA.pdf 
Ossa Bocanegra, C. E. (2014). Tratamiento de la colusión en la contratación pública: una visión del caso colombiano. Revista de Derecho, (42), 233-263. Recuperado de http:// www.redalyc.org/pdf/851/85132008010.pdf

Paz, L., y Blanco, C. (2015). Renegociación de contratos de concesión vial. Revista Republicana, (19), 171-192. Recuperado de http://ojs.urepublicana.edu.co/index.php/ revistarepublicana/article/view/254/226

Puentes, R. (2017). Análisis de la apropiación y uso de las TIC por parte de las pymes colombianas. Revista IUSTA, 1(46), 19-44. DOI: http://dx.doi.org/10.15332/s1900-0448. 2017.0046.01. Recuperado de http://revistas.usta.edu.co/index.php/iusta/article/view/ $3524 / 3423$

Sarmiento, D., Medina, S., y Plazas, R. (2017). Sobre la responsabilidad y su relación con el daño y los perjuicios. Revista Via Inveniendi et Iudicandi, 12(2), 101-115. DOI: http:// dx.doi.org/10.15332/s1909-0528.2017.0002.04. Recuperado de http://revistas.usantotomas.edu.co/index.php/viei/article/view/3754/3716

Superintendencia de Industria y Comercio de Colombia. (2012). Resolución No 40901. Recuperado de http://www.sic.gov.co/sites/default/files/estados/RESOLUCION_40901_ DE_28_DE_JUNIO_DE_2012_SANCION_INPEC.pdf

Superintendencia de Industria y Comercio de Colombia. (2016). Resolución No 70225. Recuperado de http://www.sic.gov.co/sites/default/files/normatividad/Resolucion_70225_ 2016.pdf

Superintendencia de Industria y Comercio de Colombia. (2017). Concepto 17-310455. Recuperado de http://www.sic.gov.co/sites/default/files/normatividad/102017/Radicado_17-310455.PDF

Superintendencia de Industria y Comercio de Colombia. (2017). Resolución No 5216. Recuperado de http://www.sic.gov.co/sites/default/files/normatividad/052017/Resolucion_5216.pdf

Superintendencia de Industria y Comercio de Colombia. (2017). Resolución No 18645. Recuperado de http://www.sic.gov.co/sites/default/files/normatividad/062017/Resolucion18645de19Abril2017AperturaVigilancia.pdf 
Superintendencia de Industria y Comercio de Colombia. (s. f.). Guía práctica: combatir la colusión en licitaciones. Recuperado de http://www.sic.gov.co/recursos_user/documentos/ articulos/2010/Guia_Contratacion.pdf

Tirole, J. (2017). La economía del bien común. Bogotá D. C., Colombia: Taurus.

Trujillo A., I. A. (2018). Las instituciones en la administración financiera de las misiones diplomáticas de Colombia en el exterior. Revista IUSTA, 1(48), 145-178. DOI: https:// doi.org/10.15332/s1900-0448.2018.0048.06 Recuperado de http://revistas.usta.edu. co/index.php/iusta/article/view/4102/3906

Velandia, M. (2011). Derecho de la competencia y del consumo. Competencia desleal; abuso de la posición de dominio; carteles restrictivos; actos restrictivos; integraciones económicas y protección al consumidor. Bogotá D. C., Colombia: Editorial Universidad Externado de Colombia. 